\title{
Entrevista com Alípio Correia de Franca Neto
}

Dirceu Villa e Marina Della Valle

O primeiro encontro com Alípio Correia de Franca Neto costuma surpreender quem o conhece apenas de nome que, herdado do avô, e aliado à extensão de sua carreira como tradutor, indica uma pessoa mais velha. Mas quem surge é um tradutor de aparência jovial que acumulou conhecimento e experiência desde muito cedo, numa carreira diferenciada e prolífica. Aos 40 anos Alípio já havia recebido dois prêmios Jabuti de tradução: um em 2002, com "Pomas, Um Tostão Cada" (Iluminuras), de James Joyce, e outro em 2006, com "A Balada do Velho Marinheiro" (Ateliê), de S.T. Coleridge. Discorrendo com elegância e intimidade sobre os mais diversos autores e escolas, ele costuma citar longos poemas e parágrafos de memória, para esclarecer ou simplesmente ilustrar algum ponto de sua argumentação sempre persuasiva. Na entrevista abaixo, Alípio detalha momentos de sua trajetória como tradutor literário, alguns de seus principais trabalhos e projetos futuros.

Você ingressou profissionalmente no mercado editorial muito jovem. Pode nos contar como foi esse começo?

Quando eu era um colegial, minha escola organizou um concurso de poesia, cujo prêmio seria uma publicação em livro. Acabei 
ganhando o concurso, o livro saiu tempos depois, e, embora ele não tivesse valor literário, a experiência foi determinante para mim, no sentido de despertar o desejo de um dia eu vir a trabalhar, de uma forma ou de outra, com livros. Tempos depois, no primeiro ano de filosofia, tendo perdido meu pai e vendo-me obrigado a sustentar uma família, tive contato com um grupo de uma outra geração, alguns deles já profissionais atuando no mercado editorial - dentre eles, o falecido Heitor Ferreira da Costa, José Antônio Arantes e Heide Strecker Gomes. Foi por intermédio deles que vim a conhecer o mundo das editoras, trabalhando primeiro como revisor e depois como tradutor.

Como se deu seu interesse pela literatura em língua inglesa? Ele vem de muito cedo em sua vida, não é?

Pelo que me lembro, meu contato com literatura de língua inglesa começou pelo convívio com uma americana educada na Inglaterra, Dorothy, que por uns dois anos morou em minha casa em períodos esporádicos depois de chegar ao Brasil. Além de minha professora, foi ela quem me pôs em contato com alguns autores que eu viria a traduzir muito tempo depois.

Você recebeu dois prêmios Jabuti por traduções de autores com quem você tem uma ligação muito forte. Você acredita que essa ligação aumenta as chances de sucesso em uma tradução?

Sem dúvida que sim. Ninguém se propõe traduzir poesia se não sentir uma afinidade de algum tipo com um autor, ou se não julgar que esse autor deva ser traduzido ou relido por alguma razão em sua época. Mas não é só isso. A experiência de traduzir extensivamente um autor, que pode ser reflexo dessa "ligação", costuma ser fundamental para recriá-lo na língua de chegada, por facultar um conhecimento maior de temas desenvolvidos por ele e 
de expedientes de sua poética, os quais o tradutor, é claro, procura recriar.

O que um prêmio como o Jabuti muda na vida de um tradutor? Há mais reconhecimento?

O Prêmio Jabuti, como se sabe, é um dos mais tradicionais no Brasil. Ele significa: veja, há pessoas competentes se debruçando sobre seu trabalho para analisá-lo. Essa apreciação, para o tradutor, talvez sirva para validar estratégias e expedientes adotados por ele, bem como para que ele reavalie certas posições. É isso o que, no fundo, muda para ele. Além do mais, a opinião abalizada de especialistas pode servir de indicação a leitores, o que acaba ajudando a formar um público leitor. Evidentemente, isso é uma forma de reconhecimento.

Como você decidiu traduzir Joyce? A aura de um autor como Joyce pesa no trabalho de um tradutor?

Acho que me incluo dentre os joycianos que vêem a obra desse autor como um único "manuscrito", apresentando uma extraordinária coerência sobretudo do ponto de vista temático, embora marcado por um modo de escrita que tem como princípio organizador uma contínua incorporação e abandono de modalidades literárias, cada nova obra destruindo os fundamentos sobre que se assentavam as anteriores - um princípio que pode ser detectado já em seus primeiros ensaios críticos. Estes, aliás, nos dão a impressão de que Joyce desde muito cedo sabia o que haveria de fazer, e, desse ponto de vista, suas obras iniciais proporcionam uma compreensão maior de sua evolução como escritor, além de serem obras extremamente bem-sucedidas no que se propõem. Acreditando nisso, elaborei um projeto envolvendo a tradução das canções e poemas líricos de Música de Câmara e Pomas, Um Tostão Cada - este livro incluindo 
também dois poemas satíricos, "O santo ofício" e "Gás de um bico" -, da peça Exilados e do romance abortado Stephen, o Herói. Obviamente, meu intuito era mostrar, dentre outras coisas, que Joyce sempre foi um "cultor de gêneros", e que a flutuação de linguagem que caracteriza suas obras posteriores já se deixava perceber, sem o radicalismo dessas obras, nas criações iniciais. Quanto à "aura" que cerca a figura de Joyce, bem, acho que ela não difere da que envolve a figura de qualquer outro grande escritor. E é claro que pesa, sim.

Traduzir poemas como os de Chamber Music e The Holy Office são duas tarefas bem diferentes dentro da obra do mesmo autor. Como foi para você integrar em português a lírica e a sátira de Joyce?

Os poemas líricos de Música de Câmara e Pomas, Um Tostão Cada, foram os mais difíceis. O poema mais comum, mais límpido, é o que pode desafiar a tradução, justamente porque deixa pouca margem de manobra para a paráfrase e a interpretação. Além disso, esse caráter "comum" e essa limpidez, que podem ser uma feliz simplificação ou uma mera convenção literária numa língua, também podem soar como uma banalidade intolerável em outra. De outro ângulo, o poema mais complexo e idiossincrático em sua estrutura é paradoxalmente o que tem mais chances de ter sua qüididade transmitida de modo satisfatório na tradução. No caso dos poemas satíricos, mais complexos, a dificuldade foi de outra ordem, sobretudo o trabalho das rimas, em sua maioria de efeito cômico.

\section{Há planos para outras traduções de Joyce?}

Acabo de entregar para a Editora Iluminuras, que vem publicando os livros dessa coleção, o romance inacabado Stephen, o Herói. Tenho planos para mais um livro, com a tradução das epifanias de Joyce. Mas ele será mais um livro sobre Joyce - particularmente, sobre seu conceito de epifania - do que de Joyce, já que as epifanias, 
destacadas dos contextos ficcionais em que foram inseridas, não apresentam valor artístico independente.

Conte-nos um pouco sobre seu interesse em Coleridge. É verdade que ele vem desde a adolescência?

A “Balada do Velho Marinheiro como uma representação artística da revery dos românticos" é objeto de minha tese de doutorado, $\mathrm{e}$, à parte meu interesse nos últimos anos por poemas dramáticos e narrativos, a escolha do tema pode ter tido motivações de ordem, digamos, mais "sentimental". Foi minha professora Dorothy quem me leu o poema primeiro em inglês, e depois o traduziu literalmente e com muita dificuldade. Como eu era um moleque, é provável que ela tenha feito isso acreditando que o imaginário do poema, com uma viagem ao redor do mundo, marinheiros e monstros marinhos se prestava à imaginação juvenil... De qualquer forma, como disse o Lyn Yu Tang, sempre somos fiéis à comida de nossa infância.

Quanto tempo durou o trabalho de tradução de A Balada do Velho Marinheiro, juntamente com o trabalho de pesquisa e de análise presente no ensaio e nas notas? Quais foram as maiores dificuldades desse trabalho?

O trabalho de tradução e a escrita do ensaio cobriram três anos. As maiores dificuldades ficaram por conta do esforço de concisão necessário para traduzir tetrâmetros e trímetros em versos de oito e seis sílabas respectivamente.

The Rime of the Ancient Mariner, de Coleridge, é um verdadeiro desafio para qualquer tradutor de poesia. Gostaria que você falasse um pouco do seu procedimento com a tradução das rimas (particularmente notável no seu belo trabalho) desse poema constituído, em sua maioria, de quartetos curtos no inglês, língua sintética. 
Evidentemente, assim como não há nenhum método sistemático para a tradução de poesia passível de ser ensinado, o êxito no trabalho das rimas, que é verdadeiramente uma arte, dependerá do talento individual do poeta-tradutor. Dele se espera, no que diz respeito às rimas e a outras estruturas significantes, o mesmo que se pode esperar de um poeta - que seja alguém altamente tendencioso em termos de significante, e que seja provido de instrumentos críticos capazes de detectar a idiossincrasia das rimas em outros idiomas, e de recursos técnicos suficientes para as reproduzir em sua língua. Não basta saber que aqui e ali o poema rima, é preciso ver de que maneira ele rima, o que pode abrir um leque maior de possibilidades na língua de chegada. De qualquer forma, seu sucesso sempre dependerá do fato de a rima, em dado contexto, ser uma conseqüência natural do movimento do pensamento ou fazer parte da trama de imagens e metáforas que foi identificada no poema original, reforçando ainda mais as relações entre som e sentido.

Como conciliar a extensão do trabalho de tradução de um grande autor, incluindo pesquisa e preparação de ensaios introdutórios e notas explicativas, com as atuais maneiras mais comuns de remuneração praticadas pelo mercado, como o pagamento por lauda? O mercado editorial inibe novas traduções de grandes obras? O que precisa mudar?

Como são raros os casos em que editoras encomendam traduções poéticas a algum tradutor, o que se vê de modo geral são iniciativas individuais de profissionais que, trabalhando por conta própria, às vezes chegam a passar anos traduzindo um poeta ou poetas, devido às dificuldades inerentes à atividade bem como ao fato de não haver justamente formas de remuneração definidas para um trabalho tão prolongado, ou que a rigor não deve ter um prazo para terminar. Essa parece ser a sina da poesia - estar fadada a permanecer sem remuneração. Por outro lado, os ensaios e notas explicativas que costumo elaborar para algumas traduções, principalmente clássicos ou outras obras inéditas de importância, em geral derivam da 
necessidade de fornecer ao leitor contextos culturais mais amplos, rastreando na medida do possível o status da obra na crítica literária e divulgando leituras em torno dela que me parecem proveitosas. Mas essa é uma necessidade minha, que costuma ser de outras pessoas também, e em geral não há formas de remuneração para isso, se bem que nesses casos o habitual seja pagar ao tradutor direitos autorais por seu trabalho - quando os autores traduzidos são de domínio público... Por essa razão, ignoro o que possa ser feito para mudar esse estado de coisas, embora acredite que a solução só possa advir do empenho dos tradutores em tentar negociar junto às editoras a partir de bases justas que levem em consideração essas dificuldades e o tempo despendido em seu trabalho, e, é claro, em assegurar seus direitos autorais, o que as editoras ainda relutam um pouco em reconhecer.

Você costuma ministrar cursos, como os de difusão cultural na FFLCH, e orientar grupos de estudo de tradução. O que essa experiência trouxe para o seu trabalho até agora?

Muitas surpresas agradáveis. Não foram poucas as vezes em que, quando me propus comentar traduções minhas em sala de aula, me deparei com alguma leitura, algum modo de abordagem da parte de alunos que acabou por me levar a outras soluções ou reformulações. O contato direto com leitores do seu trabalho é uma experiência importante, e pode ser gratificante.

Você já traduziu um bom número de poemas de Larkin, alguns publicados neste número da Cadernos de Literatura em Tradução e em números anteriores. Há planos de um livro?

Há, sim. Na verdade, comecei a traduzir Larkin em 1994. A princípio tinha a intenção de dar a público uma pequena antologia, mas, como sempre o considerei um poeta essencial para nossos tem- 
pos, reconsiderei no caminho e o projeto tomou vulto, de forma que a antologia, que se chamará Menos Enganados e que talvez saia este ano pela Iluminuras, acabou por incluir oitenta poemas extraídos de todos os livros que Larkin publicou em vida e de revistas em que apareceram originariamente, além do material paratextual com que costumo secundar alguns trabalhos.

Como você vê as idéias de equivalência métrica no caso do inglês e português? "Um Túmulo Arundel", de Larkin, publicado há alguns anos na Cadernos, me parece um ótimo exemplo de uma proporção entre as duas linguas.

Sou daqueles que acham que não há regras sobre como traduzir um texto poético. Desse ângulo, acho que um poeta-tradutor possa chegar à "poesia" em sua língua até mesmo traduzindo em prosa um poema metrificado e rimado no original... se bem que a meus olhos o produto final nesse caso deva ser chamado menos de "tradução" do que, por exemplo, de "apropriação", e em nada tenha que ver com o tipo de tradução que venho tentando fazer, ou seja, um tipo de representação tão mimética quanto possível do original. Por outro lado, não acredito numa "matemática" absoluta no processo que envolve particularmente a escolha do metro na língua de chegada. Evidentemente, na busca dessa "representação mimética", a escolha de um verso com tempo de elocução mais próximo se impõe. Não se pode, porém, lutar contra a constituição interna das línguas, e, no caso do inglês e do português, sempre contaremos com número maior de palavras paroxítonas do português para traduzir palavras monossilábicas do inglês, que são em maior número. Pelo que posso dizer de minha experiência, a escolha do metro mais próximo, após a escansão do poema original, precede a tradução. Mas às vezes sou obrigado a deixá-lo de lado quando vejo que ele é insuficiente para transmitir nuanças que percebo em minha leitura e que julgo importantes para recriar uma teia de sentido que lembre a do 
original. Nesses casos, posso valer-me de um metro maior, dentro, é claro, de certos limites. Com respeito a "Um Túmulo Arundel", por exemplo, minha opção inicial foi pelo verso de oito sílabas, que costuma ter o mesmo número de tônicas dos tetrâmetros do original. No decorrer do trabalho, percebi que seria inevitável suprimir certas nuanças, e por isso adotei o decassílabo, que me parecia mais apropriado para abarcar os conteúdos nocionais de cada verso.

Joyce costuma ser mais elíptico em seus poemas e Larkin, mais extensivo. Ambos são poetas muito diversos, mesmo no vocabulário. Quais os cuidados específicos com um e com outro, em termos de linguagem?

São autores pertencentes a tradições muito diferentes. Joyce, assim como T. S. Eliot e Ezra Pound, é tributário da tradição da poesia romântica; particularmente estes últimos chegaram a reconhecer seus débitos para com ela, sobretudo em sua fase final como Simbolismo. Grosso modo, o poema simbolista, trabalhando por meio de um arranjo de imagens, permite ao sentido que brote não expresso, por assim dizer, do espaço entre elas, e por isso acaba sempre envolvendo um "deslocamento da sintaxe". Larkin, por outro lado, pertence à tradição do plain style, clássico e neoclássico, uma tradição retomada por poetas do Movement nos anos 50 como uma reação a desenvolvimentos da estética modernista, embora ele seja obviamente filho do século XX e herde de modo paradoxal tendências que de muitas formas desafiam esse estilo. Em sua poesia, a par das palavras "correntes", há ironia e sátira, concisão epigramática e outros expedientes em geral considerados "difíceis" e "pós-modernistas". Nesse sentido, ele renova essa tradição do "estilo comum". Por se tratar de uma poesia que se alimenta da prosa, nela não são abolidas, por exemplo, as conjunções, já que se busca a linearidade do discurso. Só nesse sentido é que você pode dizer que ele é "mais extensivo", embora isso não signifique de forma alguma "mais prolixo". Como exemplos de dificuldades, eu destacaria o grande nú- 
mero de estruturas fixas de rimário complexo, a imensa variação do tom de voz decorrente muitas vezes do uso de personae, a sintaxe intrincada em momentos cruciais do poema, ou mesmo as ambigüidades ocasionais.

Quais os autores ainda inéditos em português que precisam urgentemente ser traduzidos?

Sempre há muito para ser traduzido. Pessoalmente, sinto falta de alguns clássicos, como Ibsen, Pushkin, Kleist, Hofmannsthal...

Você já se referiu a sua ótima tradução da biografia de Burgess como "um trabalho marcante", especialmente por causa dos trocadilhos e nuances culturais. Poderia nos contar um pouco sobre a experiência? Os textos carregados de humor e ironia exigem mais do tradutor?

As traduções de O Pequeno Wilson e o Grande Deus e Você Teve a $\mathrm{Sua} \mathrm{Vez}$, os dois volumes que compõem a autobiografia de Anthony Burgess e que a Cosac Naify vai relançar em breve, foram feitas há muito tempo, nos primeiros anos de minha carreira. Foi um trabalho difícil não só pela extensão (mais ou menos 1.700 laudas traduzidas: Burgess reconhecia que toda autobiografia é, necessariamente, egocêntrica), mas pela enorme variação de níveis de linguagem, jogos de palavras etc. Burgess, além de grande intérprete de Joyce, foi ele mesmo um discípulo do irlandês no uso criativo da linguagem, e esse uso, paralelamente à pesquisa que fui obrigado a empreender, sobretudo em função de termos dialetais, àquela altura de minha vida constituíram um verdadeiro desafio. Quanto ao humor e à ironia, sim, eles exigem mais do tradutor, e é um erro supor que seja mais fácil traduzir prosa do que poesia. Isso depende. A prosa, por exemplo, é capaz de incorporar mais a poesia do que a poesia a prosa, e a incorporação de estruturas poéticas como troca- 
dilhos etc., além dos aludidos termos dialetais, costuma constituir sérios obstáculos ao tradutor. Por quê?

Existe algum trabalho seu que você gostaria de ter a chance de rever?

Oh, sim, todos. Isso é algo inerente à profissão.

Você trabalha com prosa, poesia e teatro. Em sua experiência, como foi trabalhar com esses diferentes tipos de texto? Houve uma transição, ou foi naturalmente?

Sempre tive um compromisso com poesia, quer traduzindo quer escrevendo. $\mathrm{O}$ teatro vem dos primeiros anos de faculdade, e, desde essa época, cheguei a ter alguns textos originais e traduções encenadas. O ensaio, um terreno em que se travam grandes batalhas, no meu caso está a serviço da difusão da literatura criativa, e me serve para fixar leituras que julgo mais bem logradas, ou para registrar a leitura que faço da obra e que determinará o processo de tradução. Comigo, o cultivo dessas modalidades deve ter-se dado não só pelo que gostaria de acreditar fosse uma "vocação", mas também pela necessidade de ganhar a vida. Ou seja, deu-se "naturalmente".

Qual sua relação com o teatro atualmente? Quais são os planos nessa área?

A Edusp lançará no começo do ano que vem minha tradução do Estranho Interlúdio, de Eugene O'Neill, e a Iluminuras, o Teatro Completo de Sheridan. Em minhas horas vagas, venho trabalhando no Prometeu Liberto, de Shelley. 